CALDEIRA, Jorge. História da riqueza no Brasil. Rio de Janeiro: Estação Brasil, 2017. p. 546.

\title{
A revolução copernicana de Jorge Caldeira, o cálculo diferencial ao contrário e o trabalho das formiguinhas
}

Muito em evidência nestes últimos tempos, a divulgação do conhecimento científico é, desde sempre, uma área importante, mas bastante controversa para as "ciências" em geral. As disputas entre cientistas, instituições e, muitas vezes, veleidades acadêmicas e pessoais interferem de várias maneiras na produção desse conhecimento. Os fatores que levam uma determinada teoria - e consequentemente o(s) seu(s) formulador(es) - a se tornar hegemônica e adquirir ares de "verdade", nem sempre se relacionam ao conhecimento científico em si - relações pessoais, interesses econômicos, propaganda e boa divulgação, diversas vezes aparecem como determinantes nesse processo, como vemos em vários relatos na obra O Golem - o que você deveria saber sobre ciência, de Harry Collins e Trevor Pinch, jornalistas especializados, justamente, em divulgação científica.

Particularmente nas ciências sociais, os textos que divulgam para o público não especialista o "estado da arte" de campos do conhecimento

* Submissão: 15/05/2020; aprovação: 26/06/2020.

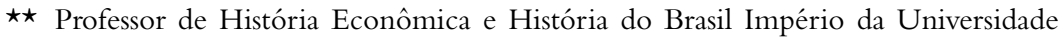
Federal Fluminense (UFF).E-mail: saraivalf@uol.com.br. 
como História, Geografia, Sociologia e Economia, têm um sentido (e um uso) político muito destacado. São defesas de determinadas interpretações nada neutras e, não raro, comprometidas com determinados interesses e visões de sociedade. Foi assim com os "manuais" de economia e as compilações dos grandes feitos como batalhas históricas e historiográficas.

Como se vê, a divulgação científica tem origem antiga e, particularmente no campo da História do e no Brasil, há diversas obras que, por muitas décadas, formaram legiões de leitores ávidos por mais conhecimento histórico. Ficaram famosos livros como História da Riqueza do Homem, de Leo Huberman (1959), As veias abertas da América Latina, de Eduardo Galeano (1971) e Genocídio americano: a Guerra do Paraguai, de Júlio José Chiavenato (1979). Tais livros portavam uma visão de mundo claramente classificada como de "esquerda", pois tinham o sentido manifesto de interferir na compreensão do passado para uma mudança revolucionária do presente.

Recentemente, acompanhando o "giro" intelectual das posições políticas mundiais, surgiram obras de divulgação - também com grande sucesso editorial - que têm usos e sentidos políticos distintos dos referidos livros supracitados. Pensamos particularmente no trabalho de Eduardo Bueno sobre a epopeia das "Grandes Navegações" e aventuras da colonização lusitana, ou ainda naqueles marcados por efemérides significativas, como os de Laurentino Gomes (1808, 1822 e 1889). Em um sentido explicitamente mais à direita, temos livros claramente conservadores como o Guia politicamente incorreto da história do Brasil, de Leonardo Narloch.

Qual a relação guardada entre os livros citados e a última publicação de Jorge Caldeira, História da riqueza no Brasil (2018), obra em análise nesta resenha? A resposta é contraditória, pois, se por um lado Jorge Caldeira é conhecido pelo grande público por obras de síntese e divulgação científica, como Mauá, empresário do Império (1995) ou Viagem pela história do Brasil (1997), também é autor de estudos mais verticais, como A nação mercantilista (1999) e O banqueiro do sertão (2 volumes, 2006).

Longe de ser "somente" um jornalista (na verdade sua formação original é em Ciências Sociais), Jorge Caldeira tem sólida formação dentro dos "cânones" da academia, é mestre em Sociologia e doutor em Ciência Política. Como poucos, Caldeira realiza pesquisas científicas “de 
ponta" ou com grande verticalidade, ao mesmo tempo em que atinge um público mais amplo, respaldado em forte sucesso comercial - em um mercado muito restritivo como é o campo editorial brasileiro.

Dito isso, é de louvar o esforço de síntese para o público não especializado de uma obra que conjuga muitas pesquisas e interpretações do passado brasileiro, atualizando os conhecimentos e levando-os para o alcance de leitores não especializados. Entretanto - e sempre há um entretanto - cabe perguntar que história Jorge Caldeira quer exatamente contar no livro em tela. Ou melhor, qual a visão de mundo que o autor quer passar para o público em geral? Ou ainda, mais especificamente, que projeto político Jorge Caldeira está defendendo com sua nova obra?

Tais perguntas, cujas respostas não são exatamente óbvias, tornam a análise das "qualidades" e "defeitos" da obra ainda mais significativa. O livro é tratado na apresentação, e pelo próprio autor, como uma revolução copernicana, o que significa dizer que manifestadamente tem a intenção de jogar por terra e questionar - quando não substituir - as interpretações consagradas pela historiografia econômica brasileira. $\mathrm{O}$ autor aponta claramente para a obra Formação econômica do Brasil, de Celso Furtado, publicado pela primeira vez em 1959 e que teve, até os dias de hoje, 51 edições. A importância e a repercussão do livro de Furtado o alçaram à rara condição de, conquanto acadêmico, ombrear sucessos literários como as obras de Guimarães Rosa, somente para ficarmos em um autor mais contemporâneo a Furtado ${ }^{1}$.

O livro contra o qual Jorge Caldeira se levanta é, sem espaço para dúvida, uma das mais poderosas obras de síntese de nossa Histórica Econômica. A importância é tal que seu título virou matéria obrigatória em todos os cursos de economia do Brasil, cujo "livro-texto", ainda em muitos cursos de graduação é, não por acaso, a obra de Furtado. Escrito baseado na sua tese de doutorado, defendida em 1948, o volume

As informações sobre o número de edições de FEB foram passadas gentilmente por Glauber Carvalho, coordenador executivo do Centro Internacional Celso Furtado e conta como $35^{\mathrm{a}}$ a edição comemorativa publicada em 2009 pela Cia das Letras, a partir de então, não existem mais "edições" e sim "reimpressões", que em 2019 estaria na $16^{a}$. Para termos de comparação, Grande Sertão Veredas, principal romance de Guimarães Rosa, publicado em 1956, tem 14 edições, Cf. <http://www.usp.br/ bibliografia/obra.php?cod $=45 \& s=$ grosa $>$, acessado em 14 de maio de 2020 . 
compilou algumas obras anteriores e contribuiu para explicar o processo de industrialização que o país observava desde os anos $1930 .^{2}$

Essa pretensão iconoclasta e um tanto "megalomaníaca" é explicitada pela apresentação da professora Mary Del Priori, que o define como um novo "clássico", bem como pelo próprio autor nas inúmeras entrevistas que concedeu a veículos de comunicação desde o lançamento do livro. Isso significa que Jorge Caldeira não está dialogando apenas com os dados contidos na obra ou os "especialistas" da área. Ele intencionalmente quer questionar os rumos da política econômica adotada pelo Estado brasileiro até os anos 1980, quando da grande crise do chamado desenvolvimentismo e dos próprios resultados da experiência militar pela qual o país ainda se recuperava.

Os dados aportados por Caldeira constroem milimetricamente essa nova interpretação de nosso passado, configurando uma defesa explícita de um novo projeto nacional. Se os dados apresentados são, de fato, muito importantes, a distribuição dos temas, dos capítulos, dos "erros" e dos "acertos" é mais significativa ainda. Somente pela divisão dos 71 capítulos do livro já se percebe algumas diferenças em relação às interpretações clássicas de nossa economia, e que, vistas em conjunto, têm um sentido especial e explícito.

Na primeira parte, referente ao período colonial brasileiro (1500-1808), são 21 capítulos. Ou seja,Jorge Caldeira dedica um volume muito importante de sua obra ao período colonial - cerca de $27 \%$ do livro, ou 14 anos por capítulo. Claro que essa é uma média sem a menor relação com a divisão cronológica proposta pelo autor se levado em consideração que a colonização no século XVI é muito limitada, para não dizer inexistente, até a sua primeira metade.

A segunda parte (referente ao período imperial brasileiro, de 1808 até 1889) tem 14 capítulos ou 20\% do total da obra, o que daria cinco anos para cada capítulo. A parte reservada para a Primeira República, também chamada de "RepúblicaVelha" (1889-1930), é a maior de todas, com 26 capítulos, ou quase $37 \%$ do total; isso para o menor período

2 Outro autor contra o qual Caldeira investe fortemente suas críticas é Caio Prado Jr. Entretanto, a crítica não é tão explícita no livro em questão quanto o é em outros textos, como no artigo publicado no Jornal Folha de S. Paulo, em 12 de outubro de 2019, quando atribui ao autor de Formação do Brasil Contemporâneo a sentença "Caio Prado Jr. é quase terraplanismo". 
analisado, pois os 41 anos do período têm praticamente um 1,5 ano por seção.

Em contraposição, a última parte que vai de 1930 até 2017, tem apenas 7 capítulos, $10 \%$ da obra ou 12 anos por cada capítulo - média pouco maior que a do período colonial -, apesar das dimensões do país e de sua economia serem indubitavelmente maiores.

Essa maior valorização quantitativa dos períodos Colonial e da Primeira República corresponde a avaliações qualitativamente positivas em relação a esses dois "momentos". Jorge Caldeira compila dados de muitos historiadores econômicos - chamados por ele e por Del Priore de "econometristas" -, reputando ao período colonial brasileiro um crescimento muito maior do que o tradicionalmente atribuído pela historiografia. Tal crescimento apresentaria duas características: teria sido consideravelmente superior do que o observado na metrópole, sobretudo ao longo do século XVIII; além de que teria se alicerçado fortemente em atividades de mercado interno, e não na agroexportação. Essa seria a primeira grande ruptura com Celso Furtado e a sua "escola", pois mostra que o famoso "exclusivo metropolitano" ou "pacto colonial" não teria sido tão deletério assim para o "Brasil", bem como a maior importância que as atividades de abastecimento (ou de mercado interno) possuíam para o conjunto da nossa economia.

Já a maior ênfase de todo o livro no período da "República Velha" marca uma diferença mais significativa ainda com as interpretações comuns de nossa História Econômica.Tanto Celso Furtado quanto Caio Prado Júnior e a geração de intelectuais que construíram nossas grandes interpretações foram "filhos", mesmo que indiretos, da "Revolução de 1930".

Foram intelectuais que, em maior ou menor grau, aderiram ao projeto de ruptura com a primeira experiência genuinamente republicana do país - na qual o pejorativo, e a posteriori, termo "Velha" - demonstrava exatamente o que se queria combater e superar. A política dos governadores (na época chamados de presidentes de estados) e do "café com leite", o voto de cabresto e o coronelismo eram expressões políticas desse atraso; a política de valorização do café a partir do convênio de Taubaté (1906) era a principal face econômica de um Estado controlado majoritariamente pelos cafeicultores da região Sudeste do país.

Para Caldeira, a Primeira República foi, ao contrário, o período do 
triunfo do Estado Liberal, que libertou as potencialidades de uma economia agrária forte e pujante, somada à entrada maciça de capital e de pessoas estrangeiras (os imigrantes) que "fertilizaram" nossa economia em um processo de desenvolvimento que foi ímpar na História.

Em sentido exatamente oposto, Caldeira reputa ao Império do Brasil (1808-1889) e ao período que atravessa os últimos 90 anos de nossa História (1930-2017) visões francamente negativas. O crescimento econômico do Império do Brasil teria sido pífio e o país teria perdido a oportunidade de se manter no rol das nações ricas do mundo (como foi o caso dos EUA). Tudo isto apesar da simpatia que devota a "personagens" como D. Pedro II ou Irineu Evangelista de Souza (o Visconde de Mauá, seu primeiro sucesso editorial de público e de crítica).

Já o período de 1930 a 2017 é "rápido" e fundamentalmente aponta para um processo de urbanização e industrialização equivocado por ser comandado pelo Estado. A opção pelo Nacional-Desenvolvimentismo e pelos grandes projetos nacionais de modernização da nossa economia estariam fortemente marcados pela burocratização constante e pelos resultados novamente pífios se comparados a outros países.

Reescrever a História do país baseados em novas intepretações e estudos é algo louvável e bem-vindo nos ambientes acadêmicos; isso o autor faz com mestria. A questão central não é revisitar temas partindo de novos estudos e evidências que apontam para direções contrárias às interpretações canonizadas de nossa História. O que de fato causa espécie no decorrer do livro de Caldeira é a quantidade de pequenos "erros" ou incongruências de um autor tão meticuloso e atento aos novos estudos que, de alguma maneira, sugere certa intencionalidade para, de maneira sofismável, chegar a conclusões não exatamente corretas.

O cálculo diferencial e integral foi uma das grandes revoluções no campo das ciências em geral, e da matemática em particular, atribuído tanto a Sir Isaac Newton quanto a Gottfried Wilhelm Leibniz, duas das mais brilhantes mentes do século XVII.Trata-se de procedimento acadêmico que formalizou o conceito fundamental de derivada de uma função a partir da definição de limites: se o limite existe, chega-se tão próximo dele quanto se desejar, mas para isso é preciso que as variáveis em questão se aproximem de um valor pré-fixado tanto quanto for necessário. Por meio de sucessivas aproximações (ou pequenos erros, que vão tornando-se cada vez menores) chega-se ao resultado muito próximo 
da "verdade". Jorge Caldeira subverte esse raciocínio e, ao longo de todo o livro, comete pequenos erros (ou aproximações) cujo resultado final é completamente equivocado.

É como se Caldeira levasse em consideração que o limite - uma determinada tese - existe sem se preocupar em quantificar os erros, que devem ser cada vez menores para que aquela conclusão faça sentido. Ou seja, como se a diferença entre o que ocorreu de fato e as informações levadas ao texto como premissas pudesse ser arbitrária. Ora, se isto ocorre, comete-se uma falácia e, portanto, o argumento é inválido e a tese não está demonstrada ${ }^{3}$.

Ao longo da leitura da obra vamos nos apercebendo de pequenos e constantes erros ou aproximações que, por si só, incomodariam muito pouco. Mas quando esses pequenos erros são somados, sustentam interpretações nem sempre defensáveis.

No período colonial, o autor dedica os dez primeiros capítulos a análises de fatos ligados a uma história eminentemente política marcada por forte viés antropológico das diferenças dos governos europeus que por aqui atuaram (português, francês, espanhol e holandês) e/ou do contato com as populações nativas. No primeiro capítulo que trata especificamente de História Econômica (ou de História da Riqueza no Brasil, tema do livro) já encontramos "pequenos grandes erros" do autor ao afirmar corretamente, em tese, que o mercado interno - subestimado por Celso Furtado e Caio Prado Júnior - teve um papel muito mais importante que a produção voltada para a exportação. Caldeira avança ainda mais no argumento e diz:

Essa acumulação [de riquezas] derivava sobretudo de várias atividades da produção interna - pecuária, agricultura alimentar (farinhas, feijão etc.), indústrias manufatureiras como tecelagem de algodão ou metalurgia do ferro, transportes etc. Mesmo na área exportadora, algumas das maiores fortunas monetárias foram obtidas por criadores de gado e comerciantes da produção local (p. 118).

3 Agradeço ao professor Seme Gebara Neto da UFMG por formalizar em termos matemáticos uma intuição acerca da importância do cálculo diferencial. Os resultados desse "exercício" obviamente não são de responsabilidade dele. 
Seguindo em frente afirma que "Os estudos quantitativos revelam que todas as atividades, internas ou externas, geravam riquezas; que os mais ricos, em todas as localidades, eram os comerciantes" (p. 119) e, por fim, completa o raciocínio de maneira emblemática dizendo que um "único dado" é o suficiente para mostrar a decadência e o declínio da produção açucareira no Brasil (mas na verdade mostrando dois dados distintos). Diz Caldeira que em 1624 a produção de açúcar no Brasil teria sido de 960 mil arrobas e que o país só voltaria a superar essa marca em 1737 quando a colônia produziu 937 mil arrobas, embora o preço tivesse caído de 1,7 mil réis em 1637 para 778 réis em 1689 (p. 119).

Nesses poucos exemplos vemos um amplo repertório de "erros" ou aproximações "grosseiras". Em primeiro lugar, a importância do mercado interno já é fortemente demonstrada pela historiografia econômica, ao menos desde os estudos pioneiros de Mafalda Zemella (1951), Myriam Ellis (1969), José Amaral Lapa (1973), não se transformando propriamente em uma novidade das últimas pesquisas, porém, nenhum historiador econômico é capaz de afirmar cabalmente que a produção voltada para a exportação não atraia capitais vultuosos e não seria a justificativa até mesmo para as invasões e ocupação Holandesa na década de 1620 até 1654 no Nordeste do país. Outra afirmação - a de que os mais ricos de todas as localidades eram os comerciantes - carece de alguma comprovação já que os estudos em inventários post-morten (a principal forma de se auferir a riqueza de pessoas e instituições nos períodos colonial e imperial) são relativamente raros para o período e as circunstâncias das "fortunas" são variadas - cidades litorâneas concentravam maiores riquezas mercantis; ordens religiosas muitas vezes possuíam propriedades rurais imensas; determinados produtos tinham grande variação de preço a depender das conjunturas.

Esse ponto (o das conjunturas) nos leva também a um outro item muito controverso no raciocínio de Caldeira, entre as décadas de 1620 e 1680 a economia portuguesa como um todo sofre uma grande crise, bem como a das suas colônias na América. A união Ibérica, as invasões holandesas, os ataques e atos de pirataria franceses e ingleses, os custos de uma grande guerra de restauração, a expulsão dos holandeses e a concorrência crescente do açúcar antilhano (produzido em escalas cada vez maiores por França, Inglaterra, Espanha e Holanda) provocaram sucessivas crises nos vários espaços lusos. O raciocínio fundamental de que o 
açúcar não era a principal atividade (ou riqueza da colônia) se apoia nesse período muito complexo e é amplamente questionável, para dizer o mínimo.

O autor ainda "nega" ao leitor a informação de que em 1688 o governo português aumentou em $20 \%$ o valor nominal da moeda e consequentemente os lucros provenientes da venda do açúcar e de outros produtos de exportação voltaram a crescer, também "esquece" de avisar que a guerra entre a França e a Inglaterra (1689-97) aumentou o preço de todos os produtos coloniais (em especial o açúcar). Afora tantos outros equívocos, um exemplo para justificar as "incongruências" poderia ser retirado das próprias fontes que Caldeira utiliza muito ao longo dos seus estudos: o jesuíta italiano Giovanni Antonio Andreoni estava no Brasil justamente nesse "terrível" período (1681-1716) para os "pobres" senhores de engenho quando anotou que essa indústria tão falimentar no raciocínio de Caldeira era uma das "principais invenções do engenho humano" e continua relacionando o "engenho" ao dom divino que concedia ao homem inteligência e prosperidade 4 .

Por fim, e o pior de tudo, é que nesse capítulo encontramos referências ao "novo tratamento de dados documentais" (p. 118), aos "estudos quantitativos" (p. 119), aos "novos conhecimentos" (p. 120), aos "estudos sociológicos" (p. 121) e é, justamente este, um dos capítulos que não possui nenhuma nota ou bibliografia que referende os raciocínios propostos. Deve-se aceitar então, em nome da erudição de Caldeira (que de fato é muito grande), as afirmações feitas baseadas no argumento de autoridade que não se apoia em nenhuma autoridade!

“Aproximações" similares se espraiam por quase todos os capítulos subsequentes e seria exaustivo (e impossível dado ao escopo dessa resenha) fazer uma descrição de todos. Escolhemos, portanto, alguns pontos emblemáticos em capítulos "chave" que reafirmam que as incoerências apontadas por Caldeira constroem uma interpretação, no mínimo, muito específica de nossa realidade e de nossa "riqueza".

Já nos fins do século XVIII e início do século XIX, na passagem da Colônia para o Império, o autor escreve, no capítulo 19 (Riqueza e Em-

4 A informação sobre a reforma monetária vem de Godinho (1953, p. 77). O impacto positivo no preço do açúcar a partir da guerra entre França e Inglaterra pode ser visto em Magalhães (1998, p. 26). Por fim, a citação é de Antonil (1837, p. 9). 
preendedores),- mais uma vez querendo reafirmar o caráter revolucionário de sua pesquisa -“Em poucas palavras, os números revelam o oposto do que pressupunham as interpretações anteriores: a economia brasileira tinha dinamismo próprio e a economia da metrópole dependia disso" (p.192).A interpretação de decadência para o período de 1780 até 1830 (mais ou menos) vem novamente de Celso Furtado, que dizia que entre o declínio da mineração do ouro e até o café se tornar o principal produto de exportação do país, o Brasil viveu um período de crise. Tal análise já é contestada por numerosos autores, incluindo aí o estudo anterior de Caio Prado Júnior de 1943, que nomeava esse período de "Renascimento Agrícola" pelo grande dinamismo e crescimento de atividades de exportação e ainda do mercado interno. O próprio estudo de José Jobson de Andrade Arruda, citado por Caldeira, vem de sua tese de doutorado de 1971 e trazia a hipótese da diversificação da colônia que aumentava, em muito, o número (e a quantidade) de gêneros exportados pelo Brasil.

A questão aqui é que no raciocínio subsequente, Caldeira coloca que a Economia Brasileira no período tinha $85 \%$ de sua riqueza gerada pelo mercado interno e, em uma nota incompreensível (nota 4), ele atribui tal informação a Nathaniel Leff sem referendar qual obra e muito menos qual parte do texto.

A obra de Nathaniel Hyman Leff é relativamente pouco conhecida no Brasil, apesar do brilhantismo desse autor. A questão é que no raciocínio central, no seu livro mais conhecido, Subdesenvolvimento e desenvolvimento no Brasil (1982), o autor afirma que a brutal e indecente concentração de renda, pessoas escravizadas e terras no país desde o período colonial, criaram aqui uma sociedade tão estratificada e desigual que uma imensa maioria da população somente sobrevivia do que produzia internamente, quase não tendo acesso a bens e produtos de um mercado externo e mesmo "nacional" praticamente inexistente.

Portanto, na interpretação de Leff, dizer que uma parcela importante da população vivia voltada diretamente para o mercado interno é bem diferente de dizer que esse mercado é a verdadeira Riqueza do Brasil, como quer Caldeira.

Ainda nesse capítulo, Caldeira se utiliza dos dados de um censo de 1819 (apesar de ser um capítulo ainda sobre o período colonial), que dizia que o país teria 3,128 milhões de habitantes, dos quais 800 mil 
seriam índios aldeados na sua grande maioria (18,2\% da população); 2,48 milhões de "livres" (ou 56,6\%) e 1,1 milhão de escravos (ou 25,3\%). A conclusão a seguir é que, mesmo com os dados subestimados das populações autóctones, cerca de 74,8\% de nossa população era livre (p. 193). No afã de fortalecer a imagem de uma economia com grande dinâmica interna e com uma menor "vocação" agroexportadora, Caldeira sequer considera o fato de que $1 / 4$ da população do país era escravizada e deduz que a situação dos indígenas não era análoga à escravidão ou aos desmandos dos aldeamentos, apesar de extensa bibliografia destacar a violência sobre estes grupos.

Já no período imperial (cuja seção tem o significativo subtítulo de Coroas e estagnação durante o desenvolvimento do Ocidente) várias outras questões causam estranheza. Entre elas vemos que no capítulo 25 ( $A$ constituição de 1824) o autor aponta dados populacionais e um valor irreal no preço dos escravos que o Brasil possuiria em 1823 - equívoco onde os dados foram retirados de outra obra sua $A$ nação mercantilista.

Jorge Caldeira afirma que a população livre nesse momento seria de 2,8 milhões de pessoas (números inferiores à população livre de 1819 que seria de 3,128 milhões como visto acima). Os escravos existentes no Brasil nesse ano equivaleriam a 68,8 milhões de libras esterlinas ou 293 milhões de dólares, o que daria uma média de 104,46 dólares por escravo. Trata-se de dado não verificado por nenhum historiador, economista ou mesmo "econometrista", sobretudo porque as "contas não batem". Se tomarmos o valor "médio" que um escravo possuía nesse ano (entre $100 \$ 000$ a $200 \$ 000$, adotando uma média de $150 \$ 000$ ) e fizermos a conversão de réis para libras, veremos que o valor proposto pelo autor levaria o número de cativos no país à incrível quantidade de 2,174 milhões de escravizados, população irreal se cotejada mesmo com as estimativas mais generosas da população brasileira no período. ${ }^{5}$

5 Tomamos como base do preço dos escravos o estudo de Noguerol (2005, p. 11, gráfico I e p. 12) e para os valores das libras o estudo de Moura Filho (2011, anexo - séries cambiais (1) 1795 - 1824), sendo que para o ano de 1823 tomamos como o valor corrente $4 \$ 740$ (quatro mil setecentos e quarenta réis) por libra. Assim 68,800,000 f $x 4 \$ 740=326.112: 000 \$ 000$ (trezentos e vinte e sei mil e cento e doze contos de réis) que divididos pelo valor médio dos escravos (150\$000) equivaleria a 2.174.080 cativos. 
Esse "pequeno grande erro" se reveste de um significado ainda maior quando se percebe que nesse e no capítulo anterior se compara a trajetória, pensamento e atuação política de José Bonifácio de Andrada ao jovem monarca D. Pedro I. Em ambos os capítulos vemos Caldeira contrapor um Bonifácio mais progressista que a maioria dos iluministas de sua época a um D. Pedro I ultraconservador ou simplesmente absolutista. Como expediente de retórica, a oposição de personagens para marcar o feixe de opções e pensamentos existentes em uma sociedade não é recurso desprezível; requer, entretanto, cuidados no seu manejo - sob a pena de cometer erros involuntários, ou conscientemente induzir a determinadas conclusões. ${ }^{6}$

Dizer, por exemplo, que José Bonifácio de Andrade publicou no ano de 1823 o livro Representação à Assemblea Geral Constituinte e Legislativa do Imperio do Brasil Sobre a Escravatura para os deputados de nossa primeira Assembleia Nacional Constituinte condenando a escravidão é irreal e errôneo, para dizer o mínimo (p.258). As contas que atribuíam um valor (e um número) absurdo aos escravizados no país fortaleceria a coragem e desprendimento deste que, teria sido um dos principais líderes da nossa independência e que teria se levantado contra a instituição escravidão no momento de nossa primeira constituinte.

Desde a década de 1970 Emília Viotti da Costa já argumentava que Bonifácio escreveu, de fato, tal opúsculo, porém, o mesmo somente foi publicado em 1825, quando Bonifácio se encontrava exilado. Essa visão de que Bonifácio lutou contra a escravidão e o tráfico já a partir de 1822 é uma "lenda" comprada pelos intelectuais, que até a década de 1920 o defendiam como o "patriarca da independência". O detalhe crucial aqui é que Jorge Caldeira é um dos maiores especialistas neste personagem, responsável pela publicação no ano de 2002 (dentro da coleção Formadores do Brasil) do volume José Bonifácio de Andrada e Silva. Ele, mais que ninguém, não cometeu um "deslize”, um "esquecimento" ou uma "simplificação" em nome da leitura e fluidez do texto; intencionalmente ele omite essa informação que mostraria muito dos limites de nossa elite e do pacto silencioso feito em relação à escravidão.

6 Esse mesmo recurso foi utilizado no seu livro sobre Mauá, o contraponto no caso foi entre o empresário e o imperador. 
Outro erro infinitesimal, de grandíssimo alcance, é reputar ao Império brasileiro um crescimento econômico irrelevante. No último capítulo desta seção (36 - Balanço do Império) o autor faz, como o próprio nome do capítulo indica, um balanço melancólico onde, apesar da atuação de "benfeitores" como Bonifácio, Pedro II e Mauá, a renda per capita teria crescido apenas 4\% entre 1820 e 1890 (p. 361).A única referência apresentada é um estudo da OCDE bastante criticado e que contradiz grande parte dos estudos sobre economia brasileira no Oitocentos ${ }^{7}$.

Somente em termos de exportações a economia brasileira cresceu entre 1820 até 1890 cerca de $583,7 \%$ pois, em 1820 o total das exportações brasileiras foi de 20,67 milhões de dólares e em 1890, 116,74 milhões, ou um crescimento de pouco mais de $8 \%$ ao ano. O orçamento do Império saltou de 3.802:434\$204 em 1823 para 145.896:141\$105 em 1888, ou um crescimento de mais de $3.800 \%$. O Império do Brasil assistiu ainda um intenso processo de crescimento de indústrias, expansão de estradas, ferrovias, meios de comunicação (como telégrafos e correios) entre tantos outros empreendimentos ${ }^{8}$.

Não se discute em momento nenhum a péssima concentração de renda de uma economia de base escravista como a nossa, e muito menos uma transição do trabalho escravo para o livre como foi conduzida no país. A questão é que nem Caldeira discute isso e nem o Império foi esse "deserto" de desenvolvimento como o autor nos quer mostrar.

Essa leitura, aliás, se baseia fortemente na comparação com os Estados Unidos da América e no espetacular crescimento que esse país teve ao longo do século XIX, como frisado pelo autor. No caso, esse crescimento destoa da maioria dos países do mundo, não podendo servir de comparação que o Brasil (ou qualquer outro país) não tenha crescido

7 O estudo citado não apresenta as fontes de onde se retirou os dados de renda per capita. De outra forma, o estudo sequer cita como, metodologicamente, realizou o corte entre as pessoas escravizadas e as livres, nunca é demais lembrar que um escravo era um ser humano que pertencia a outro ser humano e, como propriedade, (uma das mais valiosas de nossa história) interferia diretamente na renda dessa sociedade.

8 Os dados sobre as exportações brasileiras foram retirados de Federico e Tena (2018) já os dados sobre os orçamentos do Império foram tirados de Carreira (1889, p. 97 e 571), mesmo descontando a inflação do período, o crescimento da arrecadação foi muito expressivo. 
porque os seus níveis de incremento de renda e população se assemelham ao EUA.

A seção referente à Primeira República é, sem dúvida, a melhor do livro, onde a análise de Caldeira mais assume profundidade e traz dados e análises dignas de reflexão pelos Historiadores Econômicos. Ele partilha da visão que o primeiro período republicano do país não foi marcado somente pelo atraso ou pela agroexportação, ao contrário:

Os números assinalam a combinação de duas tendências dinâmicas. Uma era a do comércio internacional, perceptível no desempenho positivo do principal produto de exportação. Outra, e em ritmo ainda mais forte, era a do crescimento do mercado interno, sobretudo nos setores da indústria e de serviços como os transportes. Ou seja, as oportunidades oferecidas pelo crescimento do comércio internacional foram aproveitadas e desencadearam um surto de crescimento do mercado interno (p. 634)

Reforçando os argumentos centrais do seu livro, chega à conclusão de que a desregulamentação que o Estado assumiu desde o início do período republicano, com a expansão das exportações capitaneadas pelo café e o mercado interno, permitiram um verdadeiro boom de serviços, empresas e indústrias, como nunca antes na história do país.Apoiando-se nos dados dos censos industriais e agrícolas $(1907,1913$ e 1920) aponta corretamente para a existência de mais de 13 mil fábricas no país na década de 1920, além de inúmeros outros empreendimentos.

O Mercado Interno foi o principal responsável pelo crescimento extraordinário que o país teve, ressaltando a figura emblemática do Jeca Tatu, personagem de Monteiro Lobato e que segundo citação de Caldeira "pesa nos destinos econômicos do país com o polvilho azedo de que é fabricante, tendo amealhado mais de 200 mil-réis em prata no fundo da arca" (p. 638).

Aqui, é importante reconhecer a habilidade de Caldeira em analisar os dados e provocar interpretações agudas. Se não há “erros” ou "aproximações" como nas outras seções do livro, convém apenas problematizar algumas das conclusões apresentadas pelo autor.

Se não é consenso que o período imperial tenha sido de estagnação como quer o autor, automaticamente se impõe que muito do processo de modernização e diversificação de nossa economia tenha se iniciado 
ainda no período imperial. A relação virtuosa entre a agroexportação e o desenvolvimento de atividades voltadas para o mercado interno, incluindo aí o desenvolvimento de sistemas modernos de transportes, fábricas variadas, sistemas financeiros (compreendendo bancos e casas comerciais), urbanização (com iluminação elétrica, bondes, etc.) e a produção de alimentos já foi anotada por numerosos historiadores econômicos. Entre eles cumpre destacar o recém-falecido professor Wilson Cano e sua noção de complexo agroexportador (1977); ou ainda Wilson Suzigan e seu estudo sobre as origens das indústrias no Brasil (1986). Aliás, os dois, bem como a maioria dos historiadores econômicos que se debruçam sobre as origens da industrialização no país, tendem a reconhecer que estas origens estão no século XIX (e não na ação isolada de Mauá) e que guardam muitas continuidades entre Império e Primeira República.

A outra questão de importância a pontuar é que o elogio ao mercado interno personificado na figura do Jeca Tatu poderia muito bem ser questionado em termos de acesso a bens materiais e imateriais se pensássemos em tudo o que foi negado a essa parcela expressiva, produtiva, mas miserável do Brasil. Analfabetismo, doenças endêmicas, ignorância, violência policial e política não impediram esses grupos de terem uma extraordinária capacidade de produzir. O que não aparece no raciocínio de Caldeira é o quanto o país teria ganhado mais em termos econômicos - e obviamente social - caso a nossa sociedade fosse menos desigual.

A última parte do livro, como já dito, tem uma visão contraditória acerca do crescimento do nosso país pós-1930, talvez o melhor resumo do que Caldeira quer dizer esteja no título e no texto explicativo que abre a seção:

\section{0-2017 A era do muro: uma centralização, dois resultados}

O emprego do governo central como dique nas transformações externas permite um crescimento maior que a média internacional em tempos de economia fechada - mas sua manutenção leva a resultados pífios na era global (p. 645).

A interpretação que permite ao autor considerar um período de 87 anos em que o país foi atravessado por uma ditadura de caráter fascista; 
a maior guerra que o mundo já viu; um período inédito de bipolaridade política permeada pelo despertar de movimentos sociais com graus de organização e reivindicações singulares até então em nossa história; uma ditadura civil-militar e uma redemocratização cambaleante com dois processos de impedimentos de presidentes da república é uma análise do sucesso e do fracasso do nosso crescimento econômico via Estado brasileiro.

Nesse "rápido" passar de olhos sobre os últimos 80 anos de nossa História, Caldeira faz, de fato, uma interpretação sobre a centralidade (e o desastre) que foi a atuação dos sucessivos governos como os principais responsáveis pelo nosso crescimento, à custa, porém, do sufocamento da iniciativa privada e da ação dos empresários liberais - origem última de todo o desenvolvimento econômico de um país na visão do autor. Um dos poucos governos "elogiáveis" porque antiestatista, foi o de Fernando Henrique Cardoso e que, coincidentemente, assina a orelha da edição do livro.

Ao fim e ao cabo, o livro de Jorge Caldeira passa uma mensagem para o público em geral de que menos governo seria mais economia e que nossa pujança agrária (ou em outros termos nossa vocação agrícola) seria o suficiente para fecundar e desdobrar as demais atividades (industriais, comerciais e de serviços) de que tanto necessitamos. Concordando com o slogan exaustivamente adotado por meios de comunicação de que "o agro é tudo", o livro contribui para a viragem no modelo de desenvolvimento adotado no país e que nos trouxe até aqui.

Aliás, como o próprio Caldeira havia dito em determinada passagem do livro, a História da Riqueza no Brasil é mais um estudo sobre "o papel dos governos nesses resultados econômicos" (p. 635) do que sobre a riqueza em si. A despeito de toda a inegável modernização que o país atravessou entre 1930 até 2017, a atuação estatal sugaria as verdadeiras potencialidades e o crescimento "natural" aos quais o país estaria destinado.As aproximações "tendenciosas" adotadas pelo autor se revestem mais pelas ausências. Um autor tão meticuloso no "uso" dos dados quantitativos praticamente os abandona quando eles passam a existir de maneira institucionalizada com a criação de inúmeras entidades públicas e privadas criadas (como o IBGE, as Federações Industriais/Comercias, Sindicatos e as próprias Faculdades de Economia, Universidades e Institutos de Pesquisa que surgem nesse período). 
É como se Caldeira necessitasse de dados quantitativos quando eles são de difícil acesso e, quando abundantes, se tornam desnecessários, porque a interpretação já está pronta, ou o confronto com os "especialistas" seria mais intenso. Creio mesmo que a maioria dos historiadores econômicos (que vêm de formações distintas como historiadores, economistas, cientistas sociais e outros) e que são genericamente chamados de "economistas especializados em econometria" - a começar pelos professores Wilson Suzigan e Carlos Pelaez (p. 319) - não aceitariam de bom grado essa denominação. Os historiadores econômicos fizeram e fazem um trabalho árduo de formiguinhas, construindo interpretações novas em cima de novas fontes e um esforço que envolve por vezes, mas não só, a econometria.

Entendo que o termo formiguinha se aplique mais e melhor na descrição do que sobre o que estes profissionais fazem, e que aceitariam de melhor grado essa definição, até por carregar grande dose de humildade que, mesmo não tão abundante, é valor estimado no meio acadêmico.

Nesse sentido, é importante falar que os historiadores econômicos têm posições, partidos e lados distintos como todos os demais "mortais". As críticas e revisões acadêmicas são mais que bem-vindas e necessárias em nosso meio, porque também importam em fazer ciência e fazer política. Críticas extremamente válidas ao nosso modelo de desenvolvimento econômico têm sido feitas nas últimas décadas; da mesma forma, as interpretações de Celso Furtado têm sido fortemente relativizadas, mas sempre com intensivo cuidado, e ainda, com ampla apresentação de argumentos e fontes. Para ficarmos em dois exemplos, recentemente o professor Roberto Borges Martins ofereceu fortes evidências sobre a interpretação equivocada tomada por Celso Furtado acerca do profundo quadro de depressão econômica das Minas Gerais após o declínio da mineração na segunda metade do século XVIII (Martins, 2018). Também Elias Sampaio em livro recém lançado “enfrenta" como esse economista negligenciou a questão racial no desenvolvimento de nossa economia e as consequências que isso provocou (e provoca) até os dias de hoje (Sampaio, 2019).

Por fim, ao final da obra (posfácio) e ainda em matérias recentes que Caldeira tem escrito na grande imprensa, nota-se um tom melancólico com o futuro em que existe a possibilidade de "uma mudança no modo 
de pensar a atividade humana que abandone os ideais iluministas" em uma expressão muito adequada da nossa situação (p. 740). Genericamente ele está se referindo às posturas ultraliberais de desmanche de todo e quaisquer direitos aos trabalhadores, de um nacionalismo econômico exacerbado e antiglobalista e da valorização do lucro e do empreendedorismo acima de tudo e de todos.

Talvez Caldeira esteja se apercebendo que o crescimento do obscurantismo, do negacionismo e do conservadorismo tenha ido longe demais, talvez não tenha assumido, ou reconhecido, sua parcela de culpa nesse processo. Mas com certeza fica a incômoda sensação de que sua obra contribuiu para isso, mesmo que ele tenha querido dizer "outra coisa".

\section{Referências}

ANTONIL, André João. Cultura e opulência do Brasil, por suas drogas e minas : com várias notícias curiosas do modo de fazer o assucar, plantar e beneficiar o tabaco, tirar ouro das minas, e descubrir as da prata, e dos grandes emolumentos que esta conquista da America Meridional da' ao reino de Portugal com estes, e outros generos e contratos reaes. Rio de Janeiro: Typ. Imp. e Const. de J.Villeneuve e Ca, 1837.

ARRUDA, José Jobson de Andrade. O Brasil no comércio colonial. São Paulo: Ática, 1980. CALDEIRA, Jorge. A nação mercantilista: ensaio sobre o Brasil. São Paulo: Editora 34, 1999. CALDEIRA, Jorge. Mauá: Empresário do Império. São Paulo: Companhia das Letras, 1995.

CALDEIRA, Jorge. O banqueiro do sertão: Padre Guilherme Pompeu de Almeida. São Paulo: Mameluco, 2006.

CALDEIRA, Jorge. Viagem pela história do Brasil. São Paulo: Companhia das Letras, 1997.

CANO, Wilson. Raízes da concentração industrial em São Paulo. São Paulo: Difel, 1977.

CARREIRA, Liberato de Castro. História Financeira e Orçamentaria do Império do Brazil desde a sua Fundação - precedida de alguns apontamentos acerca de sua Independência. Rio de Janeiro: Imprensa Nacional, 1889.

CHIAVENATTO, Júlio José. Genocídio americano: a guerra do Paraguai. São Paulo: Brasiliense, 1987.

COLLINS, Harry; PINCH, Trevor; DE OLIVEIRA, Laura Cardellini Barbosa. O golem: o que você deveria saber sobre ciência. São Paulo: Edunesp, 2003.

DA COSTA, Emília Viotti. Da Monarquia à República: momentos decisivos. São Paulo: Edunesp, 1998.

ELLIS, Myriam. A baleia no Brasil colonial. São Paulo: Edições Melhoramentos, 1969.

FEDERICO, Giovanni; TENA Junguito, Antonio. Federico-Tena World Trade Historical Database. Madrid: Universidade Carlos III, 2018. 
FURTADO, Celso. Formação econômica do Brasil. Brasília: Editora Universidade de Brasília, 1963.

GALEANO, Eduardo. As veias abertas da América Latina. Porto Alegre: L\&PM, 1999.

GODINHO,Vitorino de Magalhães. Portugal, as frotas do açúcar e as frotas do ouro (1670-1770). Revista de História, v. 7, n. 15, 1953.

HUBERMAN, Leo. História da Riqueza do Homem. Nova Iorque: Monthly Review Press. 1959.

LAPA, José Roberto do Amaral. O antigo sistema colonial. São Paulo: Brasiliense, 1982.

LEFF, Nathaniel H. Subdesenvolvimento e desenvolvimento no Brasil. Rio de Janeiro: Expressão e cultura, 1991.

MAGALHÃES, Joaquim Romero. “A construção do espaço brasileiro”. BETHENCOURT, Francisco; CHAUDHURI, Kirti (Dir.). História da expansão portuguesa: Do Índico ao Atlântico (1570-1697).Vol. II. Lisboa: Círculo de Leitores, 1998.

MARTINS, Roberto Borges. Crescendo em silêncio: a incrível economia escravista de Minas Gerais no século XIX. Belo Horizonte: ICAM-ABPHE, 2018.

MOURA FILHO, Heitor Pinto de. Câmbio de longo prazo do mil-réis: uma abordagem empírica referente às taxas contra a libra esterlina e o dólar (1795-1913). Cadernos de História, v. 11, p. 9-34, 2011.

NARLOCH, Leandro. Guia politicamente incorreto da história do Brasil. Rio de Janeiro: Globo Livros, 2009.

NOGEROL, Luiz Paulo. Preços de bois, cavalos e escravos em Porto Alegre e em Sabará, no século XIX. Ensaios FEE, Porto Alegre, v. 26, número especial, p. 7-36, 2005.

PRADO JR, Caio. Formação do Brasil contemporâneo. São Paulo: Companhia das Letras, 2011.

SAMPAIO, Elias de Oliveira. Dialogando com Celso Furtado - Ensaios sobre a questão da mão de obra o subdesenvolvimento e as desigualdades raciais na formação econômica do Brasil. São Paulo: Hucitec, 2019.

SILVA, José Bonifácio de Andrada e. Representação à Assemblea Geral Constituinte e Legislativa do Imperio do Brasil Sobre a Escravatura. Paris: Typographia de Firmin Didot, 1825.

SUZIGAN, Wilson. Industria brasileira. Origem e Desenvolvimento. $2^{\mathrm{a}}$ ed. São Paulo: Hucitec/Editora da Unicamp, 2000.

ZEMELLA, Mafalda P. O abastecimento da capitania das Minas Gerais no século XVIII. São Paulo: Hucitec, 1990. 